\title{
The effect of biliary stenting on difficult common bile duct stones
}

\author{
Fatih Aslan, Mahmut Arabul, Mustafa Celik, Emrah Alper, Belkıs Unsal \\ Department of Gastroenterology, Katip Celebi University, Atatürk Research and Training Hospital, Izmir, Turkey
}

Prz Gastroenterol 2014; 9 (2): 109-115

DOI: $10.5114 / p g .2014 .42507$

Key words: common bile duct stone, biliary stenting, endoscopic retrograde cholangiopancreatography.

Address for correspondence: Fatih Aslan MD, Department of Gastroenterology, Katip Celebi University, Ataturk Training and Research Hospital, Izmir Atatürk Eğitim ve Araştırma Hastanesi, Basin Sitesi, 35160, Karabağlar, Izmir, Turkey, mobile: +90 5058727128 , phone: +9023224444 44/1910, e-mail: drfatihaslan@hotmail.com

\begin{abstract}
Introduction: If common bile duct (CBD) stones (choledocholithiasis) are left untreated, they may cause increases in morbidity and mortality due to several conditions.

Aim: In this study, using transient biliary stenting following the failure of an initial endoscopic retrograde cholangiopancreatography (ERCP) session, we aimed to show the effects of making the CBD stones smaller and easier to remove in the following session.

Material and methods: In 156 of 1300 (12\%) patients with CBD stones, who underwent balloon screening and/or basket lithotripsy following ERCP and CBD cannulation, it was not possible to remove the stones in the first session. Of these 156 patients, 64 (4.9\%) were further followed and tested following transient biliary stenting.

Results: In the last ERCP following biliary stenting, the maximum stone sizes and stone indices were decreased in 54 (83\%) patients and stone fragmentation was observed in 46 (72\%) patients. Complete and incomplete removal was obtained in $40(62.5 \%)$ and $24(37.5 \%)$ patients, respectively.

Conclusions: Biliary stenting, fragmentation and the reduction in the size of difficult common bile duct stones caused by the first session of ERCP may increase the chance of success in the next session of ERCP.
\end{abstract}

\section{Introduction}

If common bile duct (CBD) stones (choledocholithiasis) are left untreated, they may cause increases in morbidity and mortality due to several conditions, including obstructive jaundice, repeated attacks of cholangitis, pancreatitis and secondary biliary cirrhosis [1]. At the moment, CBD stones can be effectively and safely treated by endoscopic retrograde cholangiopancreatography (ERCP). Although successful removal rates of CBDs are 85-90\% [2], the remaining 10-15\% of CBDs cannot be extracted through ERCP because of the larger $(\geq 15 \mathrm{~mm})$ calculi, the shortness $(\leq 36 \mathrm{~mm})$ and narrow angle $\left(\leq 135^{\circ} \mathrm{C}\right)$ of distal $\mathrm{CBD}$, impacted calculi and anatomical difficulties [3]. These are known as 'difficult common bile stones' and cannot be removed using standard methods. Alternative methods such as electrohydraulic lithotripsy (EHL) and extracorporeal shock wave lithotripsy (ESWL) can remove $90 \%$ of them [4]. However, these methods requireexperience and additional equipment that may not be available in every centre.
When CBD stones cannot be removed, a transient stent is placed in the patient in order to prevent impaction, to provide a bridge for more advanced methods and to facilitate bile drainage. It has been shown that such stenting makes the stones smaller and easier to remove [4]. However, it has not been clarified that this method is effective in all types of stones, nor whether the success of the treatment will be affected by the size and number of stones, and how long the transient biliary stent will stay in situ.

\section{Aim}

In this study, in transient biliary stenting following the failure of a first ERCP session, we aimed to show the effects of making the CBD stones smaller and easier to remove in the following session.

\section{Material and methods}

This was a prospective study in the University of Katip Celebi, Ataturk Training and Research Hospital, 
Gastroenterology Clinic between January 2008 and January 2010. Patients with clinical and laboratory findings of, and diagnosed with, obstructive jaundice using transabdominal ultrasonography (USG), magnetic resonance cholangiopancreatography (MRCP) or endoscopic ultrasonography (EUS) were treated endoscopically with ERCP. The patients whose biliary stones could not be removed with standard methods (endoscopic sphincterectomy and balloon screening) and who therefore had a transient plastic stent inserted, were included. The local ethics committee approved this study. Informed consent was obtained from all participants in this study.

\section{Endoscopic retrograde cholangiopancreatography and stenting}

Stenting while monitoring cardiac and respiratory functions was performed by two experienced physicians (600 procedures/years) following verbal and written consent from patients, who did not consume any liquid or solid meal for at least $12 \mathrm{~h}$. They were given sedative anaesthesia (propofol 1-2 mg/kg, midazolam 0.01$0.1 \mathrm{mg} / \mathrm{kg}$ ) and nasal $\mathrm{O}_{2}(4 \mathrm{l} / \mathrm{min})$, and the procedures were performed with a TJF 145 standard therapeutic duodenoscope and Shimadzu Opescope 50N fluoroscope. After visualising the ampulla Vater, cannulation was carried out. In the same session, cannulation was attempted with either the pre-cut technique or fistulotomy if more than five cannulation attempts had failed. After cannulation, contrast-enhanced fluoroscopic images of the calculi were taken and their localisation, size, number and whether they were impacted or not were elicited. Removal of the stones with ballon screening following adequate endoscopic sphincterectomy was attempted. Patients with partially removed stones with mechanical lithotripsy were excluded from the study. In patients with incompletely removed stones a plastic, $10-12 \mathrm{~cm}$ long 7-10 French ( $\mathrm{Fr}$ ) stent was placed crossing the stones proximally relative to the localisation and size of them. No basket was used to evaluate the stent efficacy.

Following ERCP, all patients were monitored for at least $24 \mathrm{~h}$ for possible complications that may have developed during or after the procedure. All such complications, including bleeding, perforation and post-procedural symptomatic pancreatitis were recorded and assessed. The complications developing in the first 30 and in > 30 days are classified as early and late complications, respectively [5].

The patients who had plastic stents inserted following the first unsuccessful ERCP session were invited for control on the $1^{\text {st }}, 3^{\text {rd }}$ and $6^{\text {th }}$ months in the outpatient clinic. During these controls bilirubin, amylase, leucocyte, aspartate aminotransferase, alanine aminotransferase and $\gamma$-glutamyl transpeptidase levels were measured, and CBD and other bile ducts were examined with a transabdominal USG. Six months after the first session, a repeat ERCP was performed in an attempt to remove the stones. In patients with deteriorating clinical and laboratory findings (suggesting stent obstruction or cholangitis), a second session was performed without waiting the full 6 months, and removal of stones was attempted. Failure to remove the stones after this attempt caused the removal of the old stent and a new one to be placed. Complete removal of the stones in a repeat ERCP at $6^{\text {th }}$ months or earlier because of clinical indications was accepted as a "successful" procedure, whereas failure of their removal was accepted as an "unsuccessful" procedure.

The patients were followed after stenting and were divided into two groups: those who received a successful and those who received an unsuccessful endoscopic treatment (group A and group B, respectively). The reason(s) for application, age, gender, cholecystectomy history, CBD diameter, the number of stones in the common bile duct, stone sizes, stent diameters and the presence of diverticulum were recorded.

\section{Calculation of stone size, common bile duct diameter and stone index}

Two physicians reviewed the fluoroscopic images. Measurements of stone and CBD diameters were based on the original diameter of the scope [6]. Total stone index was calculated using the number and size of stones [7] (Figures 1-3).

\section{Statistical analysis}

Data were analysed with the SPSS 17.0 data program. Stone sizes, diameters of CBDs, stone indices and differences were analysed with the Mann-Whitney

$$
\begin{aligned}
& \text { Actual diameter of the stone }=\text { Measured diameter of the stone } \times \frac{\text { Actual diameter of the duodenoscope }}{\text { Measured diameter of the duodenoscope }} \\
& \text { Actual diameter of the CBD }=\text { Measured diameter of the CBD } \times \frac{\text { Actual diameter of the duodenoscope }}{\text { Measured diameter of the duodenoscope }} \\
& \text { Stone Index }=\left[\left(\text { number of stone }{ }_{1} \times \text { stone size }\right)+\left(\text { number of stone }{ }_{2} \times \text { stone size }\right)+\ldots+(\text { number of stone } \times \text { stone size })\right]
\end{aligned}
$$

Figure 1. Calculation of stone sizes and stone index 
$U$ test. Receiver operating characteristic (ROC) analysis was used in specificity and sensitivity, while $\chi^{2}$ test, Fisher's exact test, and univariate and multivariate analyses were used for other data. Values of $p$ less than 0.05 were accepted as statistically significant.

\section{Results}

In 156 of 1300 (12\%) patients with CBD stones, who had balloon screening and/or basket lithotripsy following ERCP and CBD cannulation, the stones could not be removed in the first session. Sixty-four of these 156 (4.9\%) patients were followed after transient biliary stenting. The treatment methods used in these patients are shown in Figure 4. Forty-three of 64 (67.2\%) patients were women, and their mean age was 67 \pm 14 years (range: $36-89$ years). Thirty-seven of the 64 (57.8\%) patients had stones in their gall bladders, while 27 of 64 (42.2\%) were cholecystectomised at least 2 years before. The cannulation attempts during the first ERCP were successful in all patients. Cannulation was performed with the pre-cut technique in only $1(1.6 \%)$ patient, while all of the others $(98.4 \%)$ had standard cannulation. Nine of 64 (14\%) patients had periampullary diverticula. Impacted CBD stones were found in $30(46.5 \%)$ patients, while the other patients had no such diverticula. Plastic biliary stenting (size $10 \mathrm{Fr}$ ) was performed in 49 of 64 (76.5\%) patients (Figure 5).

In the last ERCPs following biliary stenting, the maximum stone sizes and stone indices were decreased in 54 (83\%) patients, and stone fragmentation was observed in $46(72 \%)$ patients. Complete and incomplete removal was obtained in 40 (62.5\%) and 24 (37.5\%) patients, respectively. Mean \pm SD of the numbers of stones in the first and last ERCP sessions, maximum stone sizes, CBD diameters and stone indices are shown in Table I.

Endoscopic success was obtained in 19 (70.4\%) of the cholecystectomised patients and in 21 (56.5\%) patients with gall bladder stones $(p=0.260)$. There were no statistical differences between characteristics and ERCP findings of the cholecystectomised patients and patients with gall bladder stones after stenting $(p>0.05)$ (Table II).

When patients were divided into group $A$ and group B (with successful and unsuccessful endoscopic treatment, respectively), decreases in stone size and fragmentation were observed in $100 \%$ and $87.5 \%$ of patients, respectively, in group $A$, and in $54.2 \%$ and $50 \%$ of patients, respectively, in group $\mathrm{B}(p<0.001$ and $p=0.01$, respectively). There were no significant differences between both groups with regard to age, sex distribution, presence of periampullary diverticulum or history of cholecystectomy $(p>0.05)$ (Tables III and IV). There were significant differences between the two

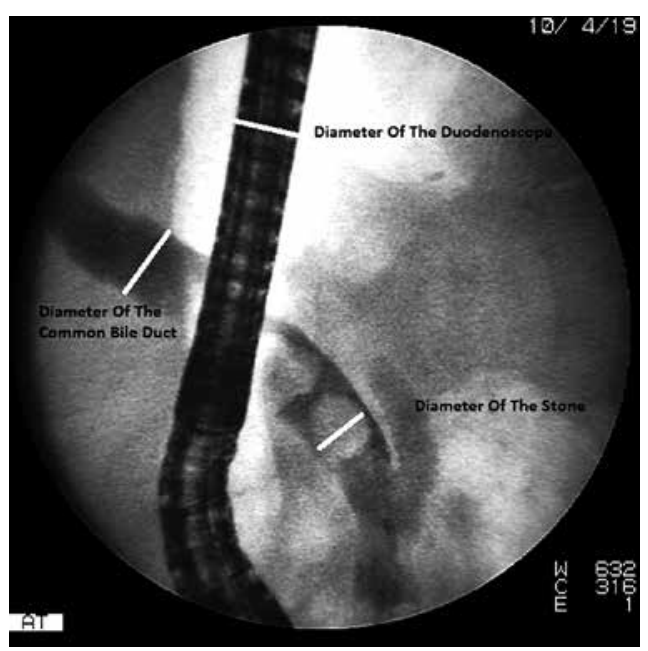

Figure 2. Measurement of diameter of CBD and stone size
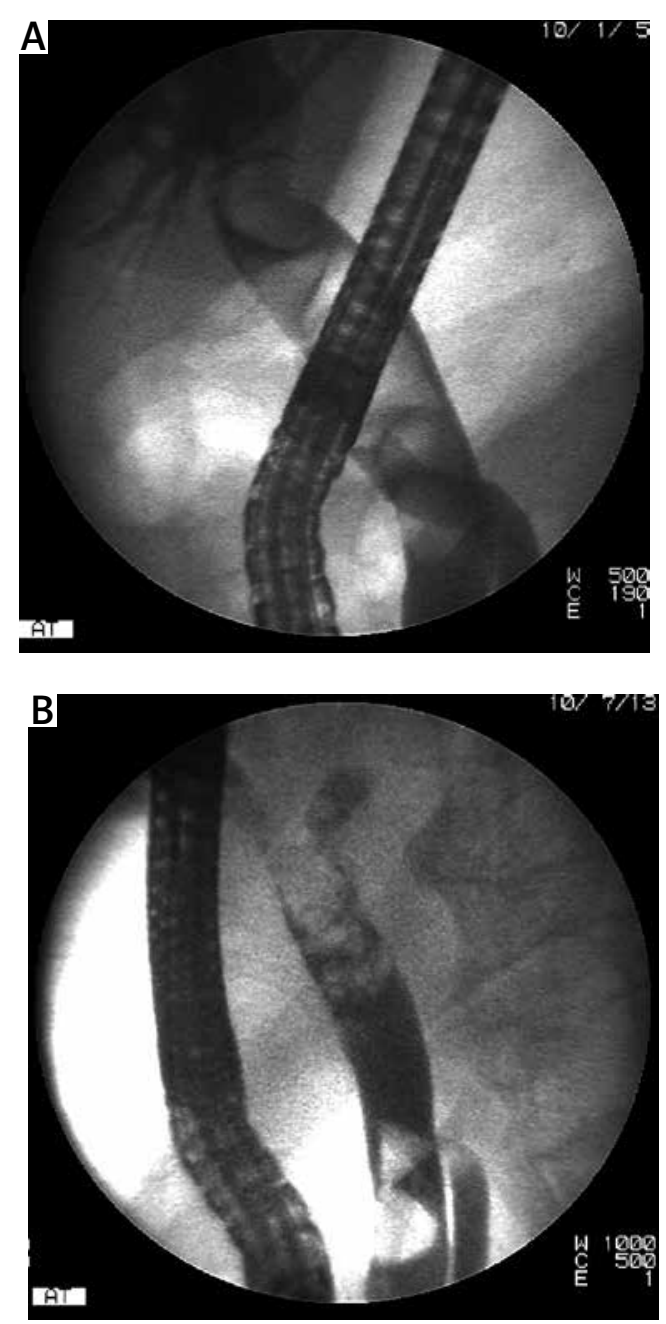

Figure 3. Images of stones: A - before (first ERCP), $\mathbf{B}$ - in the same patient after 6 months of biliary stenting (last ERCP) 


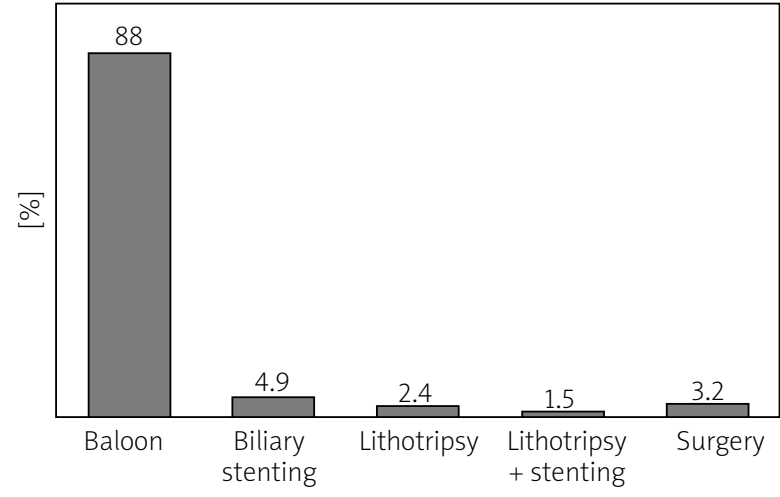

Figure 4.Treatment of common bile duct stones $(n=1300)$

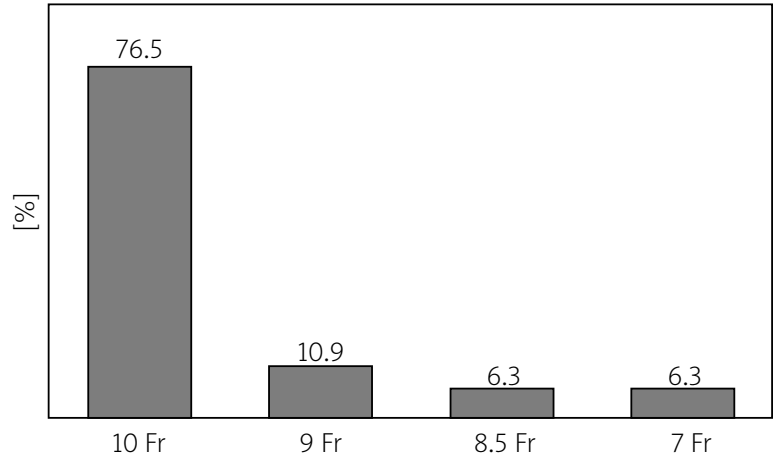

Figure 5. Distribution of patients according to biliary stent diameters $(n=64)$

Table I. ERCP findings before and after stenting

\begin{tabular}{lccc} 
Parameter & $\begin{array}{c}\text { In first ERCP session } \\
(n=64)\end{array}$ & $\begin{array}{c}\text { In last ERCP session } \\
(\boldsymbol{n}=64)\end{array}$ & Value of $\boldsymbol{p}$ \\
\hline Numbers of stone, mean \pm SD (median; range) & $2.5 \pm 1.6(2 ; 1-7)$ & $2.2 \pm 1.5(2 ; 0-6)$ & 0.092 \\
\hline Size of the largest stone, mean \pm SD (range) $[\mathrm{mm}]$ & $19.8 \pm 5.9(10-40)$ & $13.2 \pm 7.3(0-35)$ & $<0.001$ \\
\hline CBD diameter, mean \pm SD (range) $[\mathrm{mm}]$ & $22.1 \pm 5.3(12-37)$ & $17.6 \pm 6.1(8-36)$ & $<0.001$ \\
\hline Stone Index, mean \pm SD (range) $[\mathrm{mm}]$ & $37.1 \pm 19.7(10-91)$ & $22.9 \pm 14.2(0-60)$ & $<0.001$
\end{tabular}

$C B D$ - common bile duct, SD - standard deviation

Table II. Characteristics and ERCP findings of cholecystectomised patients and patients with gall bladder stones after stenting

\begin{tabular}{lccc} 
Parameter & $\begin{array}{c}\text { Cholecystectomized patients } \\
(\boldsymbol{n}=\mathbf{2 7})\end{array}$ & $\begin{array}{c}\text { Patients with gall bladder } \\
(\boldsymbol{n}=\mathbf{3 7})\end{array}$ & $\begin{array}{c}\text { Value } \\
\text { of } \boldsymbol{p}\end{array}$ \\
\hline Age, mean \pm SD [years] & $70 \pm 12.1$ & $65 \pm 14.8$ & 0.121 \\
\hline Gender (female/male) & $22 / 5$ & $21 / 16$ & 0.058 \\
\hline Periampullary diverticula, $n(\%)$ & $2(7.4)$ & $7(18.9)$ & 0.280 \\
\hline Impacted stones, $n(\%)$ & $14(51.9)$ & $16(43.2)$ & 0.052 \\
\hline Decrease in stone sizes, $n(\%)$ & $23(85.2)$ & $30(81.1)$ & 0.661 \\
\hline Fragmentation, $n$ (\%) & $21(77.8)$ & $26(70.3)$ & 0.504 \\
\hline Number of stones, mean \pm SD $($ median; range) & $2.5 \pm 1.7(2 ; 1-7)$ & $2.5 \pm 1.5(2 ; 1-6)$ & 0.932 \\
\hline Size of the largest stone, mean \pm SD (range) $[\mathrm{mm}]$ & $19.2 \pm 4.9(10-30)$ & $20.3 \pm 6.5(10-40)$ & 0.420 \\
\hline CBD diameter, mean \pm SD (range) $[\mathrm{mm}]$ & $22.9 \pm 5.6(12-36.5)$ & $21.5 \pm 5.1(12-36)$ & 0.321 \\
\hline Stone Index, mean \pm SD (range) & $37.7 \pm 21.1(12-90)$ & $36.5 \pm 18.9(10-91)$ & 0.812 \\
\hline Successful endoscopic treatment, $n(\%)$ & $19(70.4)$ & $21(56.8)$ & 0.260
\end{tabular}

$C B D$ - common bile duct, SD - standard deviation

groups with regard to mean numbers of stones in the first session, the largest stones in the first and last sessions, CBD diameters in the first and last sessions and stone indices in the last session $(p=0.034, p=0.001$, $p<0.001, p=0.001, p=0.001$ and $p=0.009$, respectively). There was no significant difference between the two groups in mean CBD diameters, while the difference between stone indices was significant $(p<0.001)$. Stones disappeared spontaneously in 6 (9.4\%) patients.
Pre- and post-procedural differences in ERCP findings are shown in Table III.

According to the ROC analysis, the possibility of stone removal increases with $90 \%$ sensitivity and $50 \%$ specificity when the decrease in stone index is at least $3.5 \mathrm{~mm}$, and with $75 \%$ sensitivity $80 \%$ specificity when the decrease in stone index is at least $28 \%$. When the largest stone is over $19.5 \mathrm{~mm}$, the possibility of removal of the stones decreases (sensitivity $75 \%$, specificity $58 \%$, OR $=4.1$ ). 
Table III. Characteristics and ERCP findings of patient groups

\begin{tabular}{|c|c|c|c|}
\hline Parameter & $\begin{array}{c}\text { Group A } \\
\text { (successful treatment) } \\
(n=40)\end{array}$ & $\begin{array}{c}\text { Group B } \\
\text { (unsuccessful treatment) } \\
(n=24)\end{array}$ & $\begin{array}{l}\text { Value } \\
\text { of } p\end{array}$ \\
\hline Age, mean \pm SD [years] & $65 \pm 14$ & $71 \pm 14$ & 0.091 \\
\hline Gender (female/male) & $24 / 16$ & $19 / 5$ & 0.120 \\
\hline Cholecystectomy history, $n$ (\%) & $19(47.5)$ & $8(33.8)$ & 0.271 \\
\hline Presence of gall bladder, $n(\%)$ & $21(52.5)$ & $16(66.2)$ & 0.310 \\
\hline Periampullary diverticula, $n$ (\%) & $5(12.5)$ & $4(16.7)$ & 0.721 \\
\hline Impacted stone, $n(\%)$ & $15(37.5)$ & $15(62.5)$ & 0.052 \\
\hline Decrease in stone size, $n(\%)$ & $40(100)$ & $13(54.2)$ & $<0.001$ \\
\hline Fragmentation, $n(\%)$ & $35(87.5)$ & $12(50)$ & 0.001 \\
\hline Number of stones in first session, mean \pm SD & $2.8 \pm 1.7$ & $2.0 \pm 1.2$ & 0.034 \\
\hline Number of stones in last session, mean \pm SD & $2.3 \pm 1.8$ & $2.1 \pm 1.0$ & 0.423 \\
\hline The size of largest stone in first session, mean \pm SD [mm] & $17.8 \pm 4.6$ & $23 \pm 6.3$ & 0.001 \\
\hline The size of largest stone in last session, mean \pm SD [mm] & $9.6 \pm 5.3$ & $19.1 \pm 6.4$ & $<0.001$ \\
\hline Stone index in first session, mean \pm SD & $37.9 \pm 19.6$ & $35.6 \pm 20.3$ & 0.652 \\
\hline Stone index in last session, mean \pm SD & $19.4 \pm 13.8$ & $28.8 \pm 13.1$ & 0.009 \\
\hline Stone index difference, mean \pm SD & $18.6 \pm 15.7$ & $6.8 \pm 11.9$ & $<0.001$ \\
\hline CBD diameter difference in first session, mean $\pm \mathrm{SD}[\mathrm{mm}]$ & $20.3 \pm 4.1$ & $25.1 \pm 5.9$ & 0.001 \\
\hline CBD diameter difference in last session, mean $\pm \mathrm{SD}[\mathrm{mm}]$ & $15.5 \pm 4.6$ & $21.1 \pm 6.5$ & 0.001 \\
\hline Difference in CBD diameter, mean \pm SD [mm] & $4.8 \pm 4.4$ & $4.0 \pm 4.3$ & 0.161 \\
\hline
\end{tabular}

$C B D$ - common bile duct, $S D$ - standard deviation

Table IV. Factors affecting endoscopic success

\begin{tabular}{lcccc} 
Variable & Odds rate & 95\% Cl & Value of $\boldsymbol{p}$ \\
\hline Cholecystectomy & 1.240 & $0.854-1.800$ & 0.272 & 0.052 \\
\hline Periampullary diverticula & 0.529 & $0.272-1.029$ & 0.721 & 0.001
\end{tabular}

Early and late complications developed in four and eighteen patients, respectively. There was stent obstruction in all patients with late complications (Table V). In 8 of the patients with stent obstruction, all stones were removed in the same session; in the other 10 patients, stents were changed and clinical follow-up was continued. Common bile duct stones were decreased in size and there was fragmentation in all patients diagnosed with cholangitis. All stones were removed in 2 patients during the same ERCP session, and in 1 patient during the last ERCP session. In 1 patient, the stones could not be removed in the last ERCP session, and it was decided to proceed with surgical treatment. In 16 patients with stent obstruction, the stones were decreased in size and fragmented. Endoscopic treatment was successful in 13 patients with and in 27 patients without stent obstruction ( $p=0.396)$.
Table V. Complications after stenting

\begin{tabular}{lcc}
\multicolumn{1}{c}{ Complications } & Number & Percent \\
\hline Early: & 4 & 6.25 \\
\hline Bleeding & 3 & 4.70 \\
\hline Pancreatitis & 1 & 1.55 \\
\hline Late: & 18 & 28 \\
\hline Cholangitis & 4 & 6.25 \\
\hline Disordered hepatic function tests & 14 & 21.75
\end{tabular}

\section{Discussion}

Common bile duct stones may be primary (originating from $C B D$ ) or secondary (originating from gall bladder). It has been reported that $3-14.7 \%$ of cholecystectomised patients may have CBDs [8, 9]. Primary stones are softer than secondary stones, and this differ- 
ence may increase the chance of endoscopic success in primary calculi. Although not a statistically significant difference, endoscopic treatment in cholecystectomised patients had a higher success rate than in other patients $(O R=1.240, p>0.05)$. This nonsignificant difference might be due to having more impacted stones and having fewer cholecystectomised patients than the others.

Periampullary diverticula are observed in 5-32\% of the patients undergoing duodenoscopy [10]. In patients undergoing ERCP, whether or not periampullary diverticula affect successful cannulation and procedural success has been a matter of debate for years. However recent publications support the theory that such an effect does not operate [10-12]. In this study, we observed that periampullary diverticula do not hinder successful endoscopic treatments $(\mathrm{OR}=0.529, p=0.052)$.

It has been reported that the impacted CBD stones and stone sizes are predictive of successful endoscopic clearance of CBD $[13,14]$. In our study, $46.9 \%$ of the patients had impacted stones. When assessed according to the success of the treatment, patients with successful endoscopic treatment had fewer impacted stones than the comparator group, although this was not a factor positively affecting the treatment success $(\mathrm{OR}=1.22$, $p>0.05)$. This indifference may be due to the small number of cases.

When CBD stones cannot be removed with standard methods, a transient plastic stent maybe inserted to prevent impaction and to provide a bridge for surgical treatment [15]. It has been reported that this method causes fragmentation of large CBD stones in addition to obtaining biliary drainage [7, 16-18]. Mechanical friction between the stone and the plastic stent may cause fragmentation. Because the plastic stent is easily mobile with body movements and gut peristalsis, this friction is more than expected [7]. In a study carried out by Maxton et al. [19], a transient biliary stent was placed in 79 of 283 patients undergoing ERCP for removal of CBD stones. Two to three months after the stent was placed the CBD. Stones were removed successfully in 50 (63\%) of the patients. In a study conducted by Chan et al. [16], plastic biliary stents were placed in 46 patients whose CBD stones could not be removed during the first ERCP session. However, during the next session 28 (60.9\%) of these patients had successful removal of their stones. During another study, removal of CBD stones was not successful in the first ERCP session, and 7 Fr plastic stents were placed in 20 patients. However, in 11 of 20 patients, the stones were cleared in the next session 6 months later [17]. Katsinelos et al. [18] reported that 11 of 25 (44\%) patients' CBD stones were completely removed not in the first, but in the second ERCP ses- sion. In another recent study, plastic biliary stents were placed in 40 patients, and 65 days later there were no stones found in 37 of 40 (93\%) patients [7]. Similarly to the studies mentioned in the literature, we removed 40 of $64(67.5 \%)$ patients' CBD stones successfully in the next ERCP session.

We accepted as successful any endoscopic treatment of the bile duct in which the size of all stones was decreased. In our study, a decrease in stone size and stone index was observed in $78 \%$ and $87.5 \%$ of patients, respectively, and fragmentation was observed in $73.4 \%$ of patients. When the findings were grouped according to the results of endoscopic therapy, reduction in the size of the stones and fragmentation was higher in the successful endoscopic treatment group $(p<0.05)$. The stone index was less prominent in the successful endoscopic stone treatment group, according to prior stenting $(p<0.05)$. The difference in stone index inthe successful endoscopic treatment group was higher than in the unsuccessful endoscopic treatment group ( $p<0.001)$.

It has been reported by Lauri et al. [20] that all stones with $<10 \mathrm{~mm}$ diameter can be removed. However, stone extraction is possible in only $12 \%$ of patients when the stone diameter exceeds $15 \mathrm{~mm}$, and the chances of successful endoscopic treatment decrease with stone diameters $\geq 18 \mathrm{~mm}$. The ROC analysis in our study showed that the chance of success of endoscopic treatment may increase in patients with CBD stones having diameters $<19.5 \mathrm{~mm}$.

Transient biliary stenting may cause complications, including cholangitis and pancreatitis, which demand emergency ERCP. In a study of 83 patients by Ang et al. [21], plastic biliary stenting caused cholangitis, biliary pancreatitis, obstructive jaundice and biliary colic in $71 \%, 3.6 \%, 21.4 \%$ and $3.6 \%$ of patients, respectively, during a mean of 19 months (range: 1-103 months) follow-up. Hui et al. [22] reported cholangitis in $63.2 \%$ of their patients. Early complications, including bleeding and pancreatitis, and late complications (mostly cholangitis) were reported in $28 \%$ and $34 \%$ of patients, respectively, in another study [23]. In our study, 4 (6.25\%) patients had cholangitis, and 14 patients had elevation of cholestatic enzyme levels and jaundice due to stent obstruction. The first, $3^{\text {rd }}$ and $6^{\text {th }}$ months of follow-up might cause the lower incidence of cholangitis in our study as compared to that seen in the literature.

The type and diameter of the transient catheter may affect the treatment success and complications due to stent obstruction. In a study by Hui et al. [22], $7 \mathrm{Fr}$ pigtail plastic stents were placed in 19 patients and stent obstruction was reported in 12 of them. In another study, $7 \mathrm{Fr}$ and $10 \mathrm{Fr}$ plastic stents were placed in 79 of 83 and 4 of 83 patients, respectively, and stent obstruc- 
tion was reported in $71 \%$ of these patients [21]. Kubota et al. placed a $7 \mathrm{Fr}$ stent in 34 patients, and in 25 of 34 of them partial or complete obstruction of the stents was observed [24]. Li et al. placed $8 \mathrm{Fr}$ stents in 50 patients; patency rates in the $6^{\text {th }}, 12^{\text {th }}$ and $24^{\text {th }}$ months were reported as $94 \%, 79 \%$ and $58 \%$, respectively [25]. In our study, 18 patients had stent obstruction, and 4 patients had cholangitis; these rates were smaller than those seen in the literature; the use of larger stent diameters may explain this dissimilarity. In 16 of 18 (88\%) patients with stent obstruction in our study population, the stone sizes were decreased and fragmentation was observed. Endoscopic treatment was successful in 13 (72.2\%) patients with, and in 27 (68\%) patients without, stent obstruction ( $p=0.396)$. According to these results, stent obstruction may predict a decrease in stone sizes, albeit without statistical significance. Therefore, there is a need for studies with more cases to explain this prediction.

\section{Conclusions}

Replacing the transient biliary stent in patients whose CBD stones cannot be removed with standard endoscopic methods may cause decreases in size or cause the stones to completely disappear. Stenting may cause some side-effects such as cholangitis, and this inflammation may occur in long-standing stents. Placing stents with a large bore and leaving them in the CBD for less than 6 months has been found to decrease those side-effects. According to the results of our study, stone diameters less than $19.5 \mathrm{~mm}$, decreases in stone indices of at least $30 \%$ and fragmentation all increase the chance of success in endoscopic treatment.

\section{References}

1. Lambou-Gianoukos S, Heller SJ. Lithogenesis and bile metabolism. Surg Clin North Am 2008; 88: 1175-94.

2. Joyce AM, Heiss FW. Endoscopic evaluation and therapies of biliary disorders. Surg Clin North Am 2008; 88: 1221-40.

3. Kim HJ, Choi HS, Park JH, et al. Factors influencing the technical difficulty of endoscopic clearance of bile duct stones. Gastrointest Endosc 2007; 66: 1154-60.

4. Hochberger J, Tex S, Maiss J, et al. Management of difficult common bile duct stones. Gastrointest Endosc Clin N Am 2003; 13: 623-34.

5. Cotton PB, Lehman G, Vennes J, et al. Endoscopic sphincterotomy complications and their management: an attempt at consensus. Gastrointest Endosc 1991; 37: 383-93.

6. Katsinelos P, Kountouras J, Paroutoglou G, et al. Combination of endoprostheses and oral ursodeoxycholic acid or placebo in the treatment of difficult to extract common bile duct stones. Dig Liver Dis 2008; 40: 453-9.

7. Horiuchi A, Nakayama Y, Kajiyama M, et al. Biliary stenting in the management of large or multiple common bile duct stones. Gastrointest Endosc 2010; 71: 1200-3.
8. Schirmer BD, Winters KL, Edlich RF. Cholelithiasis and cholecystitis. J Long Term Eff Med Implants 2005; 15: 329-38.

9. Riciardi R, Islam S, Canete J, et al. Effectiveness and long-term results of laparoscopic common bile duct exploration. Surg Endosc 2003; 17: 19-22.

10. Panteris V, Vezakis A, Filippou G, et al. Influence of juxtapapillary diverticula on the success or difficulty of cannulation and complication rate. Gastrointest Endosc 2008; 68: 903-10.

11. Boender J, Nix GA, de Ridder MA, et al. Endoscopic papillotomy for common bile duct stones: factors influencing the complication rate. Endoscopy 1994; 26: 209-16.

12. Lobo DN, Balfour TW, Iftikhar SY. Periampullary diverticula: consequences of failed ERCP. Ann R Coll Surg Engl 1998; 80: 326-31.

13. Lee SH, Park JK, Yoon WJ, et al. How to predict the outcome of endoscopic mechanical lithotripsy in patients with difficult bile duct stones? Scand J Gastroenterol 2007; 42: 1006-10.

14. Garg PK, Tandon RK, Ahuja V, et al. Predictors of unsuccessful mechanical lithotripsy and endoscopic clearance of large bile duct stones. Gastrointest Endosc 2004; 59: 601-5.

15. Lee TY, Sung J. Choledocholithiasis. In: ERCP. Baron T, Kozarek R, Carr-Locke DL (ed.). China, Elsevier Inc, 2008; 357-66.

16. Chan AC, Ng EK, Chung SC, et al. Common bile duct stones become smaller after endoscopic biliary stenting. Endoscopy 1998; 30: 356-9.

17. Jain SK, Stein R, Bhuva M, et al. Pigtail stents: an alternative in the treatment of difficult bile duct stones. Gastrointest Endosc 2000; 52: 490-3.

18. Katsinelos P, Galanis I, Pilpilidis I, et al. The effect of indwelling endoprosthesis on stone size or fragmentation after long-term treatment with biliary stenting for large stones. Surg Endosc 2003; 17: 1552-5.

19. Maxton DG, Tweedle DE, Martin DF. Retained common bile duct stones after endoscopic sphincterotomy: temporary and longterm treatment with biliary stenting. Gut 1995; 36: 446-9.

20. Lauri A, Horton RC, Davidson BR, et al. Endoscopic extraction of bile duct stones: management related to stone size. Gut 1993; 34: 1718-21.

21. Ang TL, Fock KM, Teo EK, et al. An audit of the outcome of longterm biliary stenting in the treatment of common bile duct stones in a general hospital. J Gastroenterol 2006; 41: 765-71.

22. Hui CK, Lai KC, Ng M, et al. Retained common bile duct stones: a comparison between biliary stenting and complete clearance of stones by electrohydraulic lithotripsy. Aliment Pharmacol Ther 2003; 17: 289-96.

23. Pisello F, Geraci G, Li Volsi F, et al. Permanent stenting in "unextractable" common bile duct stones in high risk patients. A prospective randomized study comparing two different stents. Langenbecks Arch Surg 2008; 393: 857-63.

24. Kubota Y, Takaoka M, Fujimura K, et al. Endoscopic endoprosthesis for large stones in the common bile duct. Intern Med 1994; 33: 597-601.

25. Li KW, Zhang XW, Ding J, et al. A prospective study of the efficacy of endoscopic biliary stenting on common bile duct stones. J Dig Dis 2009; 10: 328-31.

Received: 14.07.2013

Accepted: 30.12 .2013 